\title{
Isolation and potential biocontrol of the fungus causing anthracnose in longan in Vietnam
}

\author{
Phan Thi Huyen ${ }^{1, *}$, Vo Thi Xuan Huong ${ }^{1}$, Do Thanh Nhan ${ }^{2}$
}

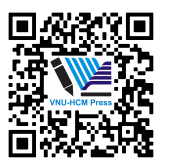

Use your smartphone to scan this QR code and download this article

${ }^{1}$ Department of Biotechnology, Faculty of Chemical Engineering, Ho Chi Minh City University of Technology, VNU-HCM

${ }^{2}$ Department of Organic Chemistry, Faculty of Chemical Engineering, Ho Chi Minh City University of Technology, VNU-HCM

\section{Correspondence}

Phan Thi Huyen, Department of Biotechnology, Faculty of Chemical Engineering, Ho Chi Minh City University of Technology, VNU-HCM

Email: huyencnshbk@hcmut.edu.vn

History

- Received: 2020-11-28

- Accepted: 2021-02-17

- Published: 2021-03-30

DOI : 10.32508/stdj.v24i1.2500

\section{Check for updates}

\section{Copyright}

(c) VNU-HCM Press. This is an openaccess article distributed under the terms of the Creative Commons Attribution 4.0 International license.

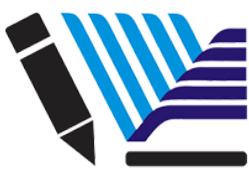

VNU-HCM Press

\begin{abstract}
Introduction: Longan is a crop plant of very high economic value, and both its fruit and flower are beneficial for human health. Longan has been increasingly cultivated in Vietnam due to the increasing demand for domestic consumption as well as export of its fruit. However, the widespread emergence and spread of anthracnose, a group of fungal disease affecting a wide range of plant species, in longan has seriously affected both the longan fruit yield and quality in Vietnam. Current methods for the prevention of anthracnose in longan depend mainly on the use of fungicides which are very harmful to human health as well as disruptive to microbial community structures in different ecosystems. In order to obtain an environmentally friendly method of control for this disease, the agent causing anthracnose in longan must first be identified. Therefore, the aim of this study was to isolate and identify the causal anthracnose agent in longan in Vietnam. Methods: Experiments were first carried out with pieces of anthracnose longan leaves pressed onto the surface of potato-dextrose agar (PDA) and incubated for days at $30^{\circ} \mathrm{C}$. Colonies, varying in appearance, were repeatedly isolated and purified on PDA agar, and the anthracnose-causing agent was initially recognized on the basis of colony characteristics and cell morphology. The suspected isolate was then tested for its ability to decompose healthy longan leaf in vitro, and its rDNA region was cloned and sequenced to determine its taxonomy. Antifungal activity testing was performed using the co-culture method. Results: We obtained a fungal isolate with septate hyphae, ovoid appressoria, and conidia (which were cylindrical in shape with rounded ends). This isolate showed a clear ability to decompose healthy longan leaves. At the molecular level, the isolate was determined to be a fungal species belonging to genus Colletotrichum, and therefore named Colletotrichum sp. strain BKHCM. We also found that its growth was inhibited when co-cultured with Streptomyces flaveus, an actinomycete originating from soil. Conclusion: For the first time, we isolated a fungal species belonging to genus Colletotrichum from anthracnose-infected longan leaves in Vietnam. We also showed that the growth of this fungus could potentially be biocontrolled.
\end{abstract}

Key words: Anthracnose, longan, Colletotrichum, Streptomyces flaveus

\section{INTRODUCTION}

The edible fruit produced by Dimocarpus longan, commonly known as longan, has a sweet taste and is healthy due to its high nutritional and medicinal values $^{1}$. The longan flower is also a good source of polyphenols and alkaloids, and is therefore a promising source for the production of beneficial health-care products ${ }^{2,3}$. Longan has been increasingly cultivated in Vietnam to meet the increasing demand for both domestic consumption of the fruit and for fruit exports to other countries. However, anthracnose, i.e. fungal disease affecting a wide range of plant species, in longan has affected both fruit yield and quality. The disease can spread rapidly, and thrives when conditions are wet and cloudy, and when humidity is high. Its symptoms are clearly seen on both the longan flower and young fruit since the lesions are slightly concave with black dots, causing the flower and young fruit to turn black and fall off. On longan leaf, the symptoms are also clearly recognizable, as shown in Figure 1.

Worldwide, anthracnose disease has been reported in chili, papaya, coffee, mango, pink apple, and strawberry, and is believed to be caused by a variety of fungal species belonging to the genus Colletotrichum ${ }^{4-7}$, including C. musae, C. capsici, C. asianum, C. boninense, C. kahawae, C. siamense, C. fragariae, C. ignotum, and C. tropicale. Different species have been reported to colonize different fruits, but a single species can also colonize more than one fruit ${ }^{5,7}$. For longan, only one case has been reported (in Thailand), and in that study anthracnose was caused by C. fructicola ${ }^{7}$. In Vietnam, the fungal species causing anthracnose in mango, chili, and coffee have also been studied ${ }^{8-10}$, but the fungal species causing anthracnose in longan has not yet been reported. 


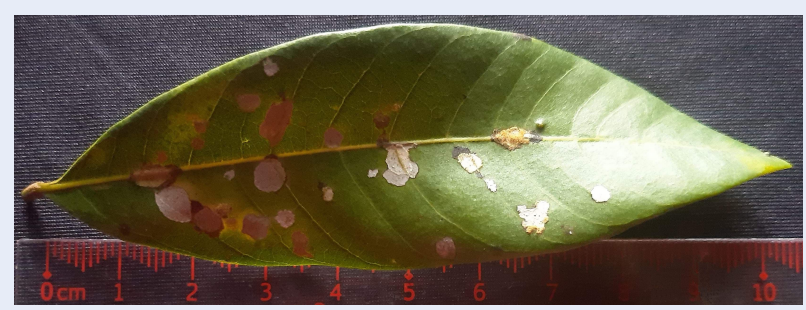

Figure 1: The anthracnose longan leaf in Tay Ninh province.

The current prevention strategy in Vietnam for anthracnose in longan involves the use of fungicides (e.g., Bavistin 50SL, Carbezim 50EC, and Benlate 50WG). The active substance in both Bavistin 50SL and Carbezim 50EC is carbendazim, and benomyl is the antifungal component of Benlate 50WG. After decomposition, benomyl forms carbendazim which is known to cause embryotoxicity, cell death, teratogenicity, infertility, liver-cell dysfunction, endocrine dysfunction, as well as disruption of microbial communities in different ecosystems ${ }^{11}$. The identification of the fungal strain causing anthracnose in Vietnamese longan is a necessary first step for determining a biocontrol agent and for establishing an environmentally friendly method to control the disease. We therefore isolated and identified the anthracnosecausing fungal agent from diseased longan leaves collected from Tay Ninh Province, Vietnam.

\section{MATERIALS AND METHODS}

\section{Materials}

Both healthy and anthracnose-diseased longan leaves were collected from Long Hoa Ward, Hoa Thanh District, Tay Ninh Province, Vietnam.

Potato-dextrose agar (PDA) was used to isolate and preserve the fungi from anthracnose-diseased leaves. To prepare PDA, $200 \mathrm{~g}$ of peeled and water-rinsed potatoes were sliced and placed in a pot. One liter of distilled water was then added, and the potatoes were boiled for 30 minutes. After boiling, the potatoes were filtered through a cheesecloth, and the effluent was collected. To the effluent, glucose $(20 \mathrm{~g} / \mathrm{L})$, agar $(20$ $\mathrm{g} / \mathrm{L}$ ), and distilled water were added to reach 1 liter, and the $\mathrm{pH}$ was adjusted to $5.6 \pm 0.2$. This medium was then sterilized at $121^{\circ} \mathrm{C}$ for 15 minutes, allowed to cool to $50^{\circ} \mathrm{C}$, and then distributed to sterile Petri dishes $(20 \mathrm{~mL}$ each). When the medium in the dish had solidified, it was ready for use.

The medium used for the fungal activity test was starch-casein agar (SCA), which contained the following ingredients (g/L): soluble starch (10), casein (0.3),
$\mathrm{KNO}_{3}(2), \mathrm{NaCl}(2), \mathrm{K}_{2} \mathrm{HPO}_{4}(2), \mathrm{MgSO}_{4} .7 \mathrm{H}_{2} \mathrm{O}$ (0.05), $\mathrm{CaCO}_{3}$ (0.02), $\mathrm{FeSO}_{4} .7 \mathrm{H}_{2} \mathrm{O}(0.01)$, agar (20), and the $\mathrm{pH}$ was adjusted to $6.8 \pm 0.2$.

\section{Methods}

Isolation of the anthracnose-causing agent from diseased longan leaves

Both healthy and anthracnose-diseased leaves were washed with tap water to remove soil and dirt. The diseased tissue was cut into small pieces at the junction of diseased tissue and healthy tissue, with a sterile scalpel. Using sterile forceps, small leaf pieces were dipped in $1 \%$ sodium hypochlorite solution for $3 \mathrm{~min}$ utes, rinsed with sterile distilled water for 1 minute, and then pressed onto the PDA surface in the dish. The dish was then inverted and incubated at $30^{\circ} \mathrm{C}$ until fungal growth was seen. Resultant mycelia varying in appearance were aseptically inoculated separately onto new PDA plates, and incubated again. The appearance of fungal colonies was visually checked, and cell morphology was observed using a light microscope at magnifications of $400 \times$ and $1000 \times$ (with an oil-immersion lens). For the observation of hyphae, mycelia from PDA dishes were picked using sterile toothpicks and placed in a drop of sterile distilled water on a clean glass slide. For the observation of spores, a sterile pre-moistened cotton swab was used to wipe spores from the agar surface and to distribute the spores into a drop of sterile distilled water on a glass slide. A coverglass was placed on top of the suspension in preparation for observation under the microscope.

\section{In vitro fungal infections}

In vitro infection experiments were carried out on freshly cut leaves from the longan tree. The leaf was washed with sterile distilled water, and both its ends were cut off. The retained middle part was then sterilized by exposure to $70 \%$ ethanol for 30 seconds, and then $0.4 \%$ sodium hypochlorite for 10 minutes. The 
leaf was then rinsed with sterile distilled water continuously for 10 minutes. A sterile needle was used to puncture the leaf surface at different sites. The wounded leaf was then placed onto the surface of a Petri dish, and spores and fungal hyphae (7 days old) were then used to inoculate the puncture surface. The infected leaf was incubated at $30^{\circ} \mathrm{C}$ for 6 days. Another leaf treated as above but without fungal infection was used as a control.

\section{Fungal identification and phylogenetic anal- ysis}

Fungal species identification at the molecular level was carried out at the Molecular Diagnostics Department, Nam Khoa-Biotek Laboratory, Ho Chi Minh City (License number 05505/SYT-GPHĐ). Fungal genomic DNA was extracted and used as template for polymerase chain reaction (PCR), using primers specific to the ribosomal DNA (rDNA) region. The resulting PCR product was then sequenced.

The sequence of the PCR product, and other rDNA sequences obtained from the National Center for Biotechnology Information (NCBI) (https://blast.ncb i.nlm.nih.gov) were used to construct a phylogenetic tree, using an online program (http://www.phyloge ny.fr). This program integrated Muscle software ${ }^{12}$ for multiple sequence alignment, the Gblocks program $^{13}$ for elimination of poorly aligned positions, a maximum-likelihood principle based approach ${ }^{14}$ for selection of the best tree topology, and the TreeDyn tool ${ }^{15}$ for tree annotation and visualization. The tree was bootstrapped 1,000 times.

\section{Antifungal activity testing}

Fungal spores were inoculated onto the centers of SCA containing Petri dishes. At the same time, actinomycete spores were inoculated at three surrounding positions within a dish, $3 \mathrm{~cm}$ from the center. Dishes were inverted and incubated at $30^{\circ} \mathrm{C}$ for 10 days. If the actinomycete grew successfully and its antifungal substances diffused into the agar medium, the fungus would not be able to grow, and antifungal areas around the actinomycete colonies would therefore appear transparent. The ability of actinomycete to inhibit fungal growth was evaluated at day 10 after inoculation by measuring the colony radius from the point of inoculation, using the formula $[(R-r) / R] \times 100$, where $r$ was the distance of fungal growth from the point of inoculation to the colony margin, and $\mathrm{R}$ was the distance between the fungal inoculation point and the actinomycete inoculation point ${ }^{16}$. Actinomycete antifungal activity was defined in terms of the size of the inhibition zone ${ }^{16}$, which was determined as $2 \times$ $[(\mathrm{R}-\mathrm{r})]$.

\section{RESULTS}

\section{Isolation of the anthracnose-causing agent}

In total, 52 PDA dishes were inoculated with anthracnose leaf pieces. From these dishes, six mycelial fungal strains that differed in colony appearance and cell morphology were obtained. These strains were numbered 1 to 6 . Repeatedly, strain numbers $1,2,3,4$, 5 and 6 were isolated 15, 21, 34, 5, 25 and 12 times, respectively. Colony appearances and cell morphologies were repeatedly examined. Based on these examinations, strain number 6 (Figure 2) was suspected to be the cause of longan anthracnose. Under the light microscope, it had septate hyphae, its appressoria were ovoid, and its conidia were cylindrical in shape with rounded ends (Figure 3). This strain was purified again on PDA, and then assessed for its ability to decompose healthy longan leaf.

\section{In vitro fungal infections}

After the fresh leaf was wounded and infected with the fungus, it was incubated. After 2 days of incubation, white mycelia were observed, and the fungus grew quickly. The leaf began to show clear signs of decay from day 4, demonstrating that longan leaf was a good substrate for fungal growth (Figure 4). In contrast, the control leaf only showed bruises at the puncture sites. Next, the suspected anthracnose-causing fungus was subjected to species identification at the molecular level.

\section{Fungal identification and phylogenetic analysis}

The size of the PCR product was 911 base pairs. When searched for sequence matches on the NCBI database, it aligned with Colletotrichum rDNA sequences with $100 \%$ coverage and an E-value of zero. The aligned region contained information for encoding a part of $18 \mathrm{~S}$ ribosomal RNA (rRNA), 5.8S rRNA, and a part of $28 \mathrm{~S}$ rRNA. In this region, it had 2 base pairs different from those of Colletotrichum sp. strain LFIT02, and 7 base pairs different from those of Colletotrichum gloeosporioides (Figure 5). Thus, the isolated fungus belonged to the Colletotrichum genus, and we named this fungus Colletotrichum sp. strain BKHCM. Figure 6 shows that the Colletotrichum sp. strain BKHCM species is on the same branch with Colletotrichum gloeosporioides and Colletotrichum sp. strain LFIT02.

\section{Antifungal activity}

The Colletotrichum sp. strain BKHCM was co-cultured with different individual actinomycete 


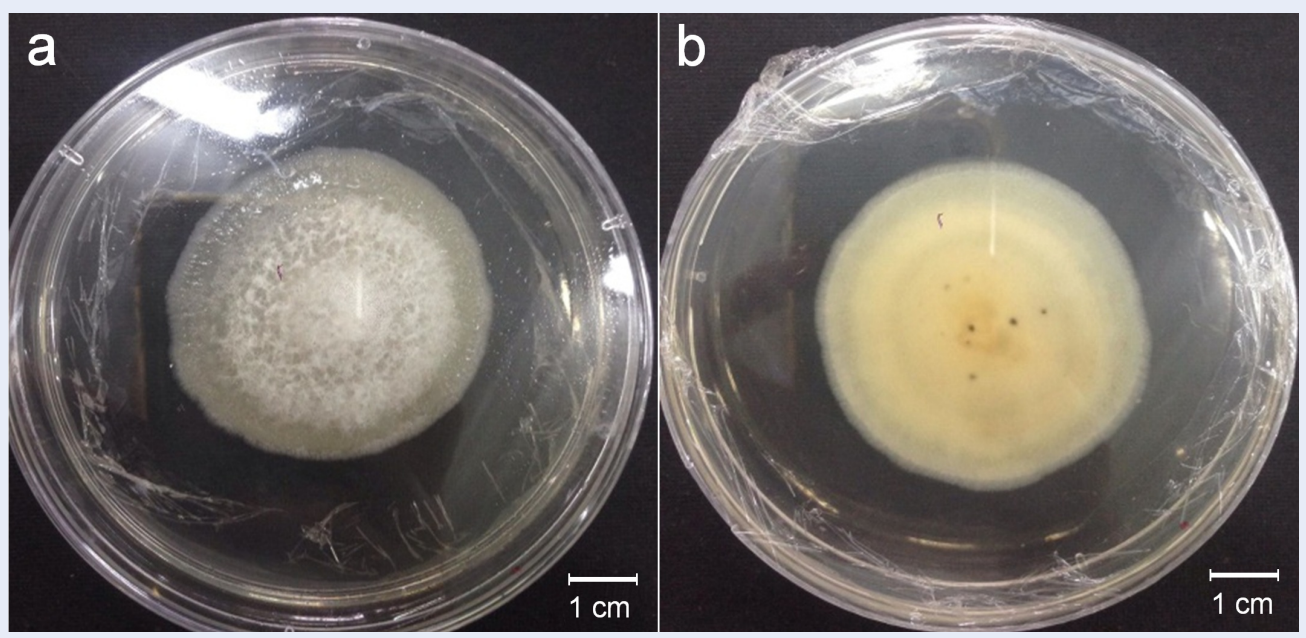

Figure 2: A seven day-old colony of strain number 6 on PDA. (a) Top view (b) Bottom view.

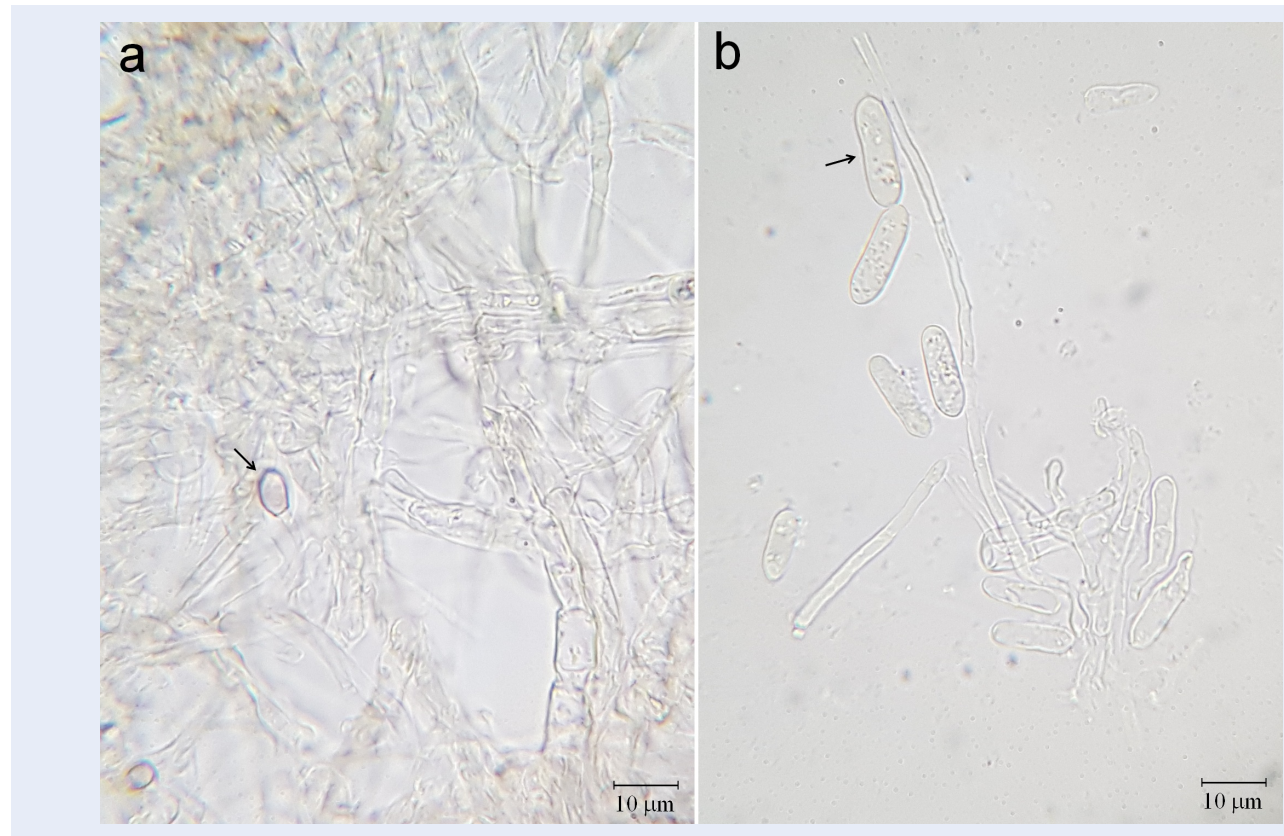

Figure 3: Cell morphology of the strain number 6 at high magnification $(1000 \times)$. Hyphae with appressoria (a, black arrow) and conidia (b, black arrow) formed on a PDA plate.

strains isolated from a variety of soil samples. The result showed transparent zones around the Streptomyces flaveus ${ }^{18}$ colonies where the fungus could not grow (Figure 7). The appearance of these transparent zones revealed that $S$. flaveus had produced antifungal substances which diffused into the agar medium. After 10 days of incubation, the distance of fungal growth from the point of inoculation to the colony margin was $1.8 \pm 0.1 \mathrm{~cm}$. The ability of streptomyces to inhibit fungal growth was therefore $40 \pm 3.3 \%$, and the streptomyces inhibition zone was $2.4 \pm 0.2 \mathrm{~cm}$.

\section{DISCUSSION}

Members of the genus Colletotrichum have been known to cause anthracnose in many different tropical fruits ${ }^{4-10}$. For the first time, we have isolated Colletotrichum sp. strain BKHCM from anthracnosediseased longan leaf collected in Vietnam. The only previous report for an anthracnose-causative agent in longan fruit identified C. fructicola, a species that 

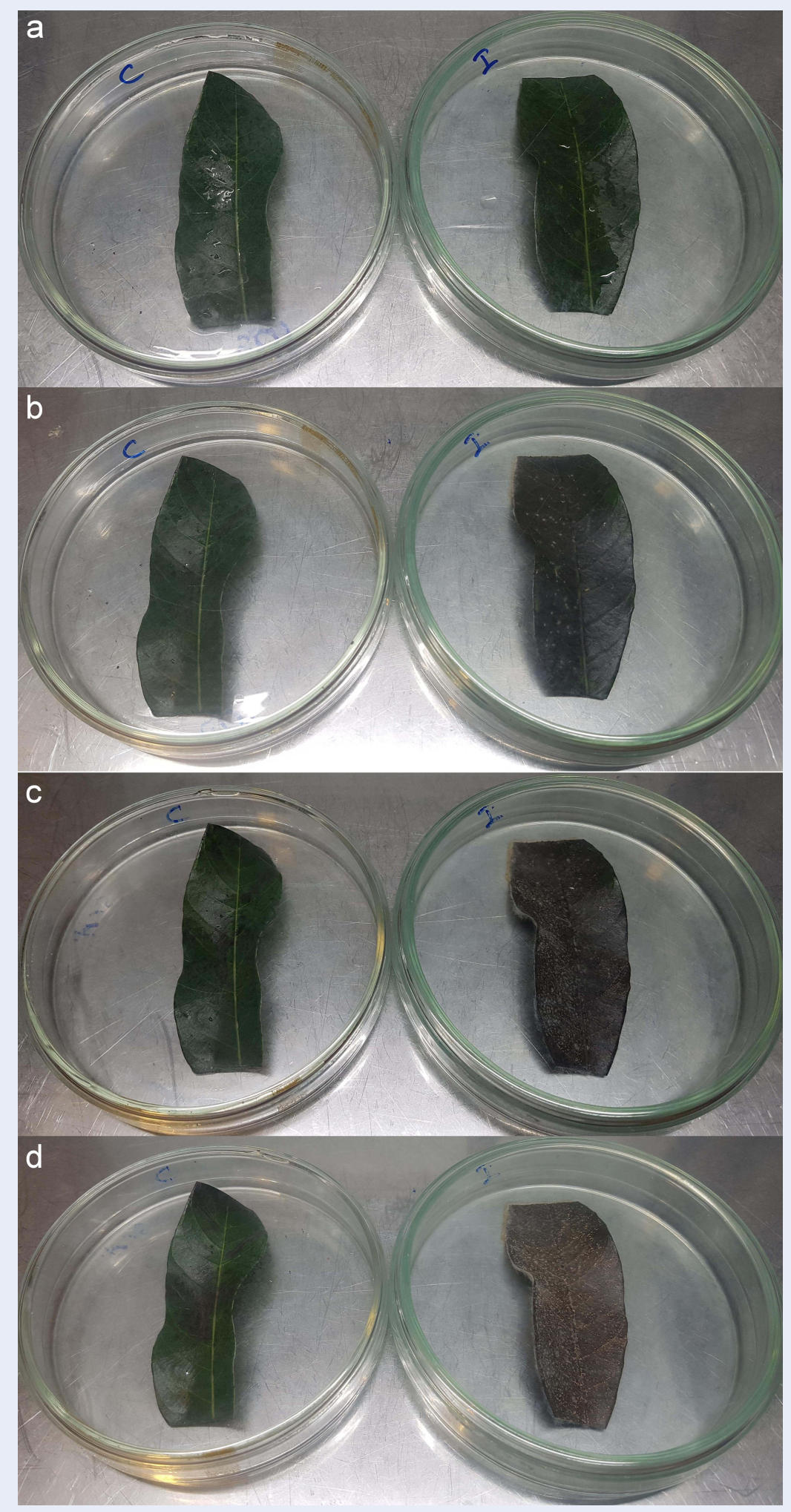

Figure 4: In vitro infection of fungus on longan leaf. Control leaf (left) and infected leaf (right) on (a) inoculation day, (b) day 2, (c) day 4, and (d) day 6 of incubation. 


\begin{tabular}{|c|c|c|c|c|c|c|c|c|}
\hline & 10 & 230 & 240 & 250 & 530 & 640 & 781 & 820 \\
\hline & c & & & & $\overrightarrow{\mathrm{CAgCT}}$ & $\overrightarrow{c+*}$ & CT月 & \\
\hline 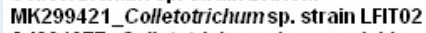 & & & & & & $C-A$ & CTA & \\
\hline J3301977_Colletotrichum g & CCGCCCGTCGC & CCC & СCCT & CTCCCGCCCC & CGGCTGACGTAG & $\mathrm{C}-\mathrm{A}$ & CCA & GAG \\
\hline
\end{tabular}

Figure 5: Difference in rDNA sequences of the related species. The sequence of the PCR product was aligned with two rDNA sequences obtained from the NCBI database, using an online program ${ }^{17}$. The NCBI accession numbers are shown before the species names. Numbers on top of the figure show the nucleotide positions in the aligned sequences.

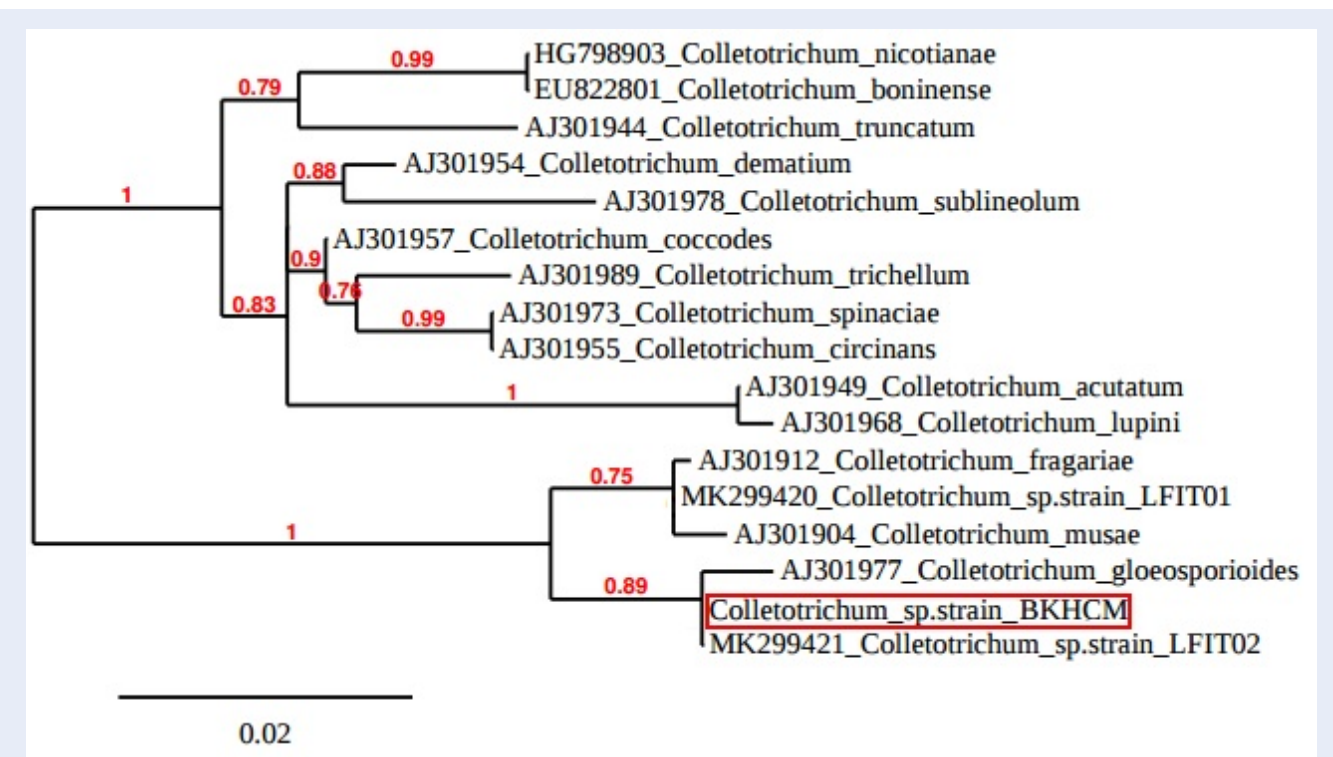

Figure 6: Phylogenetic relationships among the Colletotrichum species. Numbers in red are the bootstrapped values. NCBI accession numbers are annotated as in Figure 5.

could also infect papaya, rose apple, chili, and mango fruits, but not orange ${ }^{7}$. Compared to the strain of C. fructicola which caused anthracnose in Mexican avocados ${ }^{19}$, Colletotrichum sp. strain BKHCM colonies had a different appearance on PDA, although the shapes of their appressoria and conidia looked similar. The shapes of appressoria and conidia of Colletotrichum sp. strain BKHCM were also similar to those of many other species of the genus Colletotrichum ${ }^{4-6}$. In our in vitro fungal infection experiments, healthy leaf was decomposed quickly, but the in vitro symptoms did not look exactly the same as those observed in nature (Figure 1), probably because the leaf was already isolated from its tree and heavily punctured. If the leaf was still attached to the tree, the tree's immune system responses would have resisted the infection.

Our co-culture experiments revealed that the growth of Colletotrichum sp. strain BKHCM was sensitive to the actinomycete $S$. flaveus. We also observed that the fungus grew more actively after many rounds of transfer to new SCA dishes, probably because the strain had become more familiar with the agar medium after transfer. According to a previous study ${ }^{16}$, the antifungal activity of this actinomycete is considered to be moderate. In order to use S. flaveus as a biocontrol agent against anthracnose in longan caused by Colletotrichum sp. strain BKHCM, further research is necessary to understand how this actinomycete inhibits fungal growth so that an environmentally friendly method can be developed for using this actinomycete to control anthracnose in longan.

\section{CONCLUSIONS}

We isolated the fungus Colletotrichum sp. strain BKHCM as a causative agent from anthracnose longan leaves. This is the first report of this fungal species causing anthracnose in longan in Vietnam. We also found that the growth of this fungus was moderately inhibited when co-cultured with $S$. flaveus, indicating the possibility that longan anthracnose may po- 


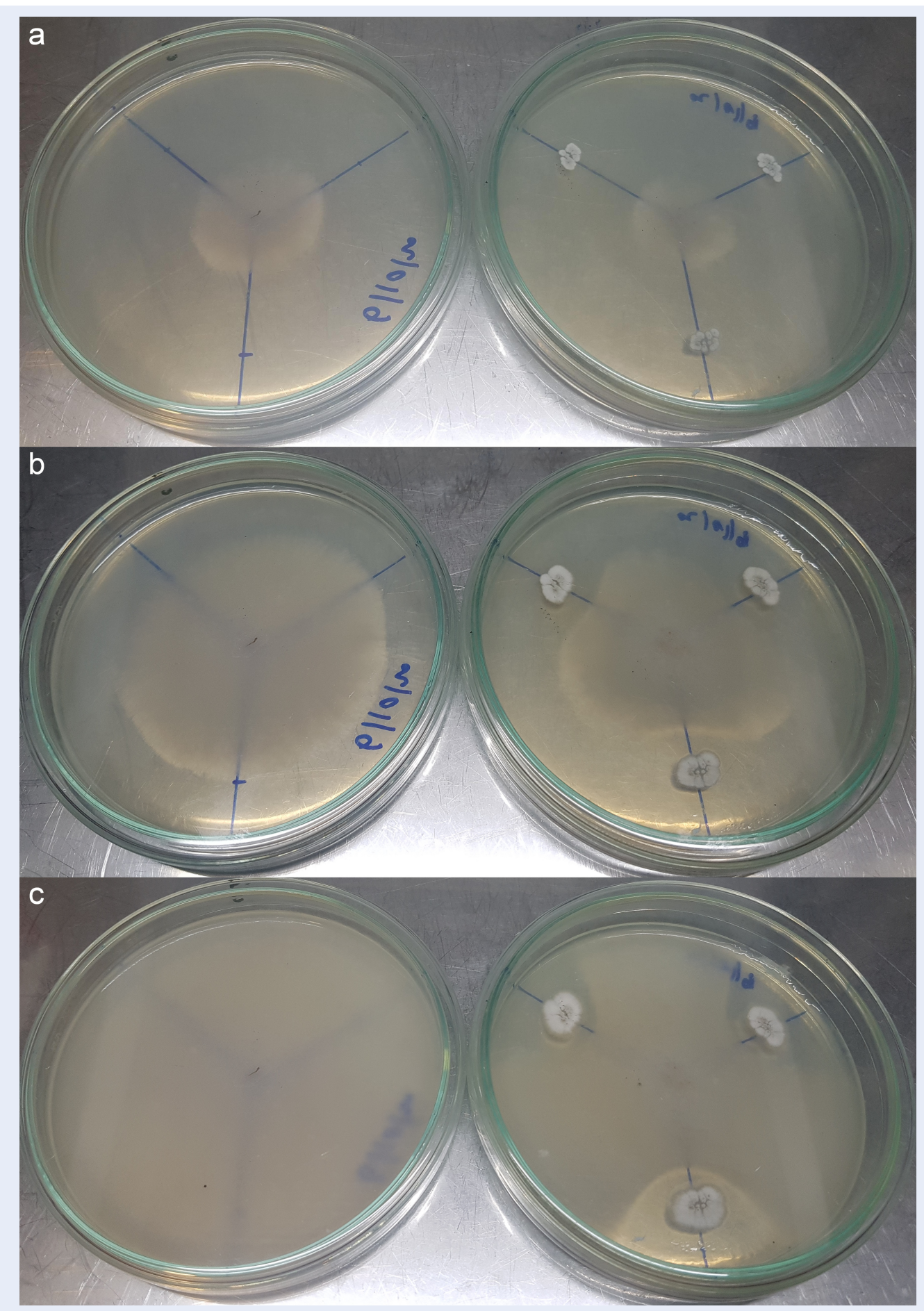

Figure 7: Antifungal activity of S. flaveus against Colletotrichum sp. strain BKHCM. Colletotrichum sp. strain BKHCM was co-cultured with S. flaveus (right) after (a) 3 days, (b) 5 days and (c) 10 days of incubation. The fungus without co-culturing with streptomyces (left) was used as a control. 
tentially be biocontrolled.

\section{LIST OF ABBREVIATIONS}

PDA: Potato-dextrose agar

SCA: Starch-casein agar

PCR: Polymerase chain reaction

rDNA: ribosomal DNA

rRNA: ribosomal RNA

NCBI: National Center for Biotechnology Information

\section{CONFLICT OF INTEREST}

The authors declare that they have no competing interest.

\section{AUTHORS' CONTRIBUTION}

P.T.H designed experiments, performed experiments, analysed data and wrote the paper. V.T.X.H and D.T.N performed experiments under the supervision of P.T.H.

\section{ACKNOWLEDGEMENT}

This research is funded by Ho Chi Minh City University of Technology - VNU-HCM under grant number To-KTHH-2019-16.

\section{REFERENCES}

1. Shahrajabian MH, Sun W, Cheng Q. Modern pharmacological actions of longan fruits and their usages in traditional herbal remedies. J Med Plants Stud. 2019;7:179-185.

2. Lin CC, Chung YC, Hsu CP. Potential roles of longan flower and seed extracts for anti-cancer. World J Exp Med. 2012;2:7885. PMID: 24520538. Available from: https://doi.org/10.5493/ wjem.v2.i4.78.

3. Tang YY, He XM, Sun J, Li CB, Li L, Sheng JF, Xin M, Li ZC, Zheng FJ, Liu GM, Li JM, Ling DN. Polyphenols and alkaloids in byproducts of longan fruits (Dimocarpus longan Lour.) and their bioactivities. Molecules. 2019;24:1186. PMID: 30917573. Available from: https://doi.org/10.3390/molecules24061186.

4. Prihastuti H, Cai L, Chen H, McKenzie EHC, Hyde KD. Characterization of Colletotrichum species associated with coffee berries in northern Thailand. Fungal Divers. 2009;39:89-109.

5. Phoulivong S. Colletotrichum, naming, control, resistance, biocontrol of weeds and current challenges. Curr Res Environ Appl Mycol. 2011;1:53-57.

6. Nam MH, Park MS, Lee HD. Taxonomic re-evaluation of Colletotrichum gloeosporioides isolated from strawberry in Korea. Plant Pathol J. 2013;29:317-322. PMID: 25288958. Available from: https://doi.org/10.5423/PPJ.NT.12.2012.0188.
7. Phoulivong S, McKenzie EHC, Hyde KD. Cross infection of Colletotrichum species, a case study with tropical fruits. Curr Res Environ Appl Mycol. 2012;2:99-111. Available from: https: //doi.org/10.5943/cream/2/2/2.

8. Thuy LHL, Kim PV. Classification of Colletotrichum species that cause anthracnose and testing of the potency of six drugs against these fungi. Science J. 2008;10:31-40.

9. Mien TT. Study on anthracnose (Colletotrichum) damaging chili at Gia Lam - Ha Noi in spring-summer crop 2008. Agricultural Master thesis, Hanoi Agricultural University. 2008;.

10. Nguyen PTH. Colletotrichum spp. associated with anthracnose disease on coffee in Vietnam and on some other major tropical crops. Faculty of Landscape Planning, Horticulture, and Agricultural Sciences, Department of Plant Protection Biology Alnarp, Swedish University of Agricultural Sciences. 2010;

11. Singh $S$, Singh $N$, Kumar V, Datta $S$, Wani $A B$, Singh $D$, Singh $\mathrm{K}$, Singh J. Toxicity, monitoring and biodegradation of the fungicide carbendazim. Environ Chem Lett. 2016;14:317-329. Available from: https://doi.org/10.1007/s10311-016-0566-2.

12. Edgar RC. MUSCLE: multiple sequence alignment with high accuracy and high throughput. Nucleic Acids Res. 2004;32:1792-1797. PMID: 15034147. Available from: https://doi.org/10.1093/nar/gkh340.

13. Castresana J. Selection of conserved blocks from multiple alignments for their use in phylogenetic analysis. Mol Biol Evol. 2000;17:540-552. PMID: 10742046. Available from: https://doi.org/10.1093/oxfordjournals.molbev.a026334.

14. Guindon S, Gascuel O. A simple, fast, and accurate algorithm to estimate large phylogenies by maximum likelihood. Syst Biol. 2003;52:696-704. PMID: 14530136. Available from: https: //doi.org/10.1080/10635150390235520.

15. Chevenet F, Brun C, Banuls AL, Jacq B, Chisten R. TreeDyn: towards dynamic graphics and annotations for analyses of trees. BMC Bioinformatics. 2006;7:439. PMID: 17032440. Available from: https://doi.org/10.1186/1471-2105-7-439.

16. Nguyen $\mathrm{XH}$, Naing $\mathrm{KW}$, Lee $\mathrm{YS}$, Tindwa $\mathrm{H}$, Lee $\mathrm{GH}$, Jeong $B K$ Ro HM, Kim SJ, Jung WJ, Kil-Yong Kim KY. Biocontrol potential of Streptomyces griseus H7602 against root rot disease (Phytophthora capsici) in pepper. Plant Pathol. J. 2012;28:282-289. Available from: https://doi.org/10.5423/PPJ.OA.03.2012.0040.

17. Corpet F. Multiple sequence alignment with hierarchical clustering. Nucleic Acids Res. 1988;16:10881-10890. PMID: 2849754. Available from: https://doi.org/10.1093/nar/16.22. 10881.

18. Phan TH, Huynh T, Phan NUP, Vo TLT. Actinomycetes isolated from soils collected in adjacent areas of Hochiminh city: sources of potential antibiotics. Sci \& Technol Dev J. 2015;p. 78-84. Available from: https://doi.org/10.32508/stdj.v18i2. 1061.

19. Fuentes-Aragón $D$, Juárez-Vázquez SB, Vargas-Hernandez $M$, Silva-Rojas HV. Colletotrichum fructicola, a member of Colletotrichum gloeosporioides sensu lato, is the causal agent of anthracnose and soft rot in avocado fruits cv. "hass". Mycobiology. 2018;46(2). PMID: 29963310. Available from: https: //doi.org/10.1080/12298093.2018.1454010. 